\title{
A Reforma Psiquíatrica e as andorinhas
}

\author{
Maria Lucia Boarini ${ }^{\star}$ \\ Izildinha Quijo ${ }^{\star \star}$
}

\begin{abstract}
Resumo
As reflexões aqui expressas têm como objetivo subsidiar discussões e encaminhamentos no setor de saúde em relação à Reforma Psiquiátrica. Têm como fundamento a experiência vivenciada (2004-2005) por uma psicóloga e sua iniciativa de implantar um Centro de Convivência como parte de uma rede substitutiva de atenção à saúde mental no municipio de Maringá. A partir desta experiência reafirma-se a pertinência deste tipo de atividade para a consolidação da Reforma Psiquiátrica no Brasil, bem como a impossibilidade de levar avante esta tarefa sem a parceria dos gestores, dos profissionais da saúde em geral e do usuário desse serviço.
\end{abstract}

Palavras-chave: Saúde pública. Saúde mental. Reforma Psiquiátrica. Educação em saúde.

\section{The Psychiatric Reform and the swallows}

\begin{abstract}
The reflections here expressed have the purpose to subsidize discussions and directions to health services concerning the Psychiatric Reform. The ideas here presented are founded in the experience (2004 to 2005) lived by a psychologist, who had the initiative of creating a Family Center as part of a substitutive net of attention to the mental health in the municipal district of Maringá. Starting from this experience the pertinence of this type of activity is reaffirmed for the consolidation of the Psychiatric Reform in Brazil, as well as the impossibility of carry this task on without the partnership of its managers, health professionals in general and the users of such service.
\end{abstract}

Keywords: Public Health. Mental Health. Psychiatric Reform. Health Education.

\footnotetext{
^ Psicóloga, doutora em Psicologia. Docente da pós-graduação do depto. de Psicologia e do depto. de Fundamentos da Educação da Universidade Estadual de Maringá. Endereço: Av. Getulio Vargas, 72 - apto. 1303. Centro Maringá. Paraná.

E-mail: mlboarini@uol.com.br

$\star \star$ Psicóloga da Secretaria de Saúde do município de Maringá - Paraná. Especialista em Saúde Pública.
} 
"Uma andorinha só não faz verão" é o que afirma a tradição popular. Supomos que as novas gerações não desconhecem esse adágio, tão antigo; mas, pensando bem, com o crescimento desenfreado da selva de pedra e o pouco cuidado que temos tido com a nossa fauna, talvez nem as andorinhas sejam mais conhecidas pela juventude, muito menos seus costumes!

Não obstante, as questões ambientais, stricto sensu, seja um assunto cuja discussão se faz cada vez mais necessária não são objeto deste estudo. Queremos apenas lembrar que as andorinhas, quando migram para outras plagas em busca de verão, nunca o fazem individualmente, mas sempre em bando. É obvio que se assim o fazem é por determinação genética. O que vale aqui destacar é que, sabiamente, a tradição popular toma o fato como metáfora para dizer da nossa impossibilidade de, solitariamente, levar avante tarefas que dizem respeito à convivência social, como a Reforma Psiquiátrica, objeto de nossa reflexão neste texto. Tomando como recurso esta metáfora, estamos afirmando a dificuldade em realizar a Reforma Psiquiátrica a partir da iniciativa particular deste ou daquele profissional. O leitor mais atento a este assunto nos lembra que já temos, no Brasil, registros de experiências bem-sucedidas de redes substitutivas do hospital psiquiátrico. Como exemplo importante temos os serviços de assistência à saúde mental dos municípios de Santos, Campinas e São Paulo (capital), no Estado de São Paulo, que marcaram época no final da década de 80 e início da de 90 do século passado já descritos e analisados por Campos (2000), Daud Jr. (2002) dentre outros. Não há como negar esta constatação, como também não há como negar que as experiências em questão foram realizadas graças a um conjunto de fatores, dentre os quais se destaca, além do apoio do gestor, o engajamento dos profissionais da saúde e usuários, cuja determinação era a extinção dos manicômios. Estas experiências comprovam também que este é, sem dúvida, o caminho para a reversão da hegemonia dos hospitais psiquiátricos, que têm no isolamento a sua principal terapêutica. Enfim, estas e outras importantes experiências que aconteceram e acontecem no Brasil e em outros países exaltam a necessidade do compromisso de todos - profissionais da saúde ou não - com a realização desta importante tarefa de compreender e atender a pessoa com transtorno mental. No Brasil já temos aprovado um conjunto de documentos oficiais que legitimam e sustentam juridicamente estas ações em saúde. Dentro da legislação existente destacamos a Lei 10.216, de abril de 2001, que "Dispõe sobre a proteção e os direitos das pessoas portadoras de transtornos mentais e redireciona o modelo assistencial em saúde mental" (BRASIL, 2004a, p. 17) e a Portaria 396, de 7 de julho de 2005 (BRASIL, 2005), que define e orienta a implantação dos Centros de Convivência e Cultura. O destaque a esta portaria do conjunto da legislação existente sobre o atendimento à pessoa com transtorno mental deve-se ao fato de dizer respeito diretamente à experiência de atuação em uma Unidade Básica de Saúde que, seguida de comentários, exporemos na seqüência. 


\section{LOCALIZANDO A EXPERIÊNCIA}

Este trabalho foi desenvolvido no período de 2004 a 2005, em uma das unidades básicas de saúde (UBS) da rede pública de saúde do município de Maringá, no Estado do Paraná, e tinha como meta a implantação de um Centro de Convivência na área de abrangência da UBS em referência. Foi levado avante pela psicóloga da UBS co-autora deste texto - a qual organizou e conduziu o processo - e acompanhado à distância, através de estagiários do quinto ano do curso de Psicologia, pela autora principal.

É necessário pontuar que esta experiência foi gerada durante um curso de capacitação promovido pela Secretaria de Saúde do município de Maringá e por nós ministrado. Neste evento e a partir de discussões sobre a Reforma Psiquiátrica definiu-se a necessidade da realização de uma pesquisa na região para levantamento de dados que norteassem as ações dos psicólogos lotados na rede básica de saúde deste município. Realizado este estudo, ${ }^{1}$ os resultados indicaram o pouco conhecimento que existia em relação aos egressos do hospital psiquiátrico para não dizer o desamparo vivido por esta população, em termos de assistência à saúde. Tais resultados foram apresentados e discutidos com todos os profissionais da saúde mental da rede publica. Alguns destes profissionais se dispuseram a rever suas praticas em seus respectivos equipamentos de trabalho. Entretanto apenas uma das psicólogas levou avante tal empreitada que ora relatamos.

\section{SOBRE A EXPERIÊNCIA... OU A BUSCA DO VERÃO}

No final de 2005, a UBS, objeto desta reflexão, dispunha de quatro equipes do Programa de Saúde da Família (PSF), ${ }^{2}$ para uma população de 14.758 habitantes, dos quais aproximadamente $15 \%$ se situavam na faixa etária de 0 a 14 anos e 85\%, na faixa acima de 15 anos. Nessa região, além de quatro escolas de nível fundamental (três municipais e uma estadual) e da UBS, a população não contava com mais nenhum equipamento do serviço público. Até aquele momento, os pacientes ditos "psiquiátricos" não eram assistidos pelo serviço de saúde mental da unidade básica de saúde em pauta. Quando procuravam o serviço médico em consulta agendada, estes pacientes vinham apenas para revalidar a receita médica a fim de receber gratuitamente a medicação. Quando recorriam à UBS em situação de emergência eram encaminhados diretamente ao hospital psiquiátrico particular existente no município. Posteriormente, o município fez convênio com um dos hospitais gerais da cidade para atendimento dos pacientes alcoolistas, que sempre representaram uma parcela alta de demanda do serviço público. Para localizar estes pacientes, necessariamente tivemos que recorrer às equipes do Programa Saúde da Família/PSF, pois eles, embora conhecidos por estas equipes, não eram objeto de nenhuma atenção especial por parte destes profissionais da saúde. A saúde, em geral, do portador de transtorno mental, ainda que não estivesse em crise, era "naturalmente" entendida como caso a ser atendido por especialistas lotados no Ambulatório de Saúde Mental ou no Hospital Psiquiátrico, quando em crise. Assim, reedita-se o histórico modelo hegemônico centrado na figura do médico, focando apenas o aspecto físico-biologico da saúde. Este 
fato confirma, novamente, que nada garante nas estratégias do programa de Saúde da Família que haverá ruptura com este modelo hegemônico, já cristalizado no imaginário dos trabalhadores de saúde e dos usuários (FRANCO; MERHY, 2000). Neste cenário iniciamos o levantamento dos casos existentes em cada uma das quatro micros áreas adstritas à UBS, ou seja, junto às quatro equipes do PSF. Antes, porém, realizamos reuniões com estas equipes para esclarecer e refletir sobre os objetivos e a importância deste estudo e da parceria destes profissionais. No transcorrer deste levantamento fomos notando a dificuldade dos agentes comunitários de saúde/ACS em identificar esses pacientes, visto que em geral não sabiam diferenciar os chamados "doentes mentais" dos "deficientes mentais". As pessoas com algum grau de deficiência mental eram identificadas pelos ACSs de modo claro, mas por desconhecerem quadros de sofrimento psíquico - tais como a esquizofrenia, o transtorno bipolar, etc. - a identificação da deficiência mental generalizava-se. Para tentar superar esta dificuldade, nesse período continuamos a capacitação dos ACSs e acompanhando-os pessoalmente em suas visitas.

Além da falta de capacitação dos ACSs para diferenciar os doentes mentais dos deficientes mentais, algumas outras dificuldades foram se explicitando, tais como: encontramos dificuldade em conhecer o histórico médico do paciente, que, já em estado cronificado da doença, passara por diversos profissionais, às vezes, em mais de uma cidade. Nos prontuários de pacientes, por exemplo, era raro o registro do diagnóstico e, às vezes, nem mesmo a indicação do medicamento definido pelo psiquiatra, estava registrada. $\mathrm{O}$ número restrito de psiquiatras na rede pública, bem como a alta rotatividade desses profissionais resultava em outra dificuldade. Como agravante desta situação, ou por conta disto, destaca-se a grande incidência de ausência às consultas médicas, de certa forma, justificada pela longa fila de espera pela consulta medica. Não havia contra-referência dos serviços ambulatoriais ou hospitalares às UBSs, provavelmente resultado da não implantação, no município, do protocolo de ação em saúde mental (MARINGÁ, 2004), o que configura dificuldades encontradas na própria organização burocrático-administrativa e impede a fluidez do atendimento. Constatou-se, também, a falta de um "fluxograma" mais técnico de encaminhamento de casos para o psicólogo que seja reflexo de um planejamento em equipe multidisciplinar onde esteja mais definido o que realmente são questões de saúde pública ou questões a serem solucionadas através de um projeto de parceria intersetorial.

Apesar das dificuldades apontadas e tantas outras questões, no período de seis meses localizamos aproximadamente trinta casos de pessoas portadoras de sofrimento psíquico, sem comprometimento da inteligência, os quais já haviam passado por internação psiquiátrica e não recebiam atenção especial na UBS.

À medida que íamos fazendo as visitas fomos constatando o desejo, tanto dos egressos do hospital psiquiátrico quanto de seus familiares, de ter um espaço onde pudessem encontrar outras pessoas e principalmente os profissionais da saúde. As pessoas sentiam falta destes encontros para discutir, pedir ajuda e sentir-se "incluídas", esclarecidas, pois em sua maioria 
elas não sabiam sequer nomear o mal que as acometia, embora não faltassem histórias dramáticas de recidivas e inúmeras internações. No transcorrer das visitas as equipes do PSF foram se aproximando das pessoas com transtorno mental, que, ao contrário do que propõem as teorias, eram muito afetivas e receptivas. Não se observou agressividade, a não ser em alguns poucos relatos familiares que denotavam mais uma reação agressiva a uma outra sentida pelo paciente.

\section{A CONSOlidação do GRUPO}

Por conta desta constatação e a despeito de tantas dificuldades, planejamos e conseguimos formar um grupo, que inicialmente contava com treze egressos do hospital psiquiátrico e familiares de alguns deles. As reuniões aconteciam todas as terças-feiras das 15 às 17 horas, numa casa ao lado da UBS, alugada pela Prefeitura, então destinada às reuniões das ACSs. Com o tempo, fomos começando o grupo cada vez mais cedo, pois o "nosso grupo", como nos autodenominávamos, chegava geralmente antes das 15 horas. Alteramos, então, o horário de início para as $13 \mathrm{~h} 30 \mathrm{~min}$. A assiduidade do grupo nos estimulou a apresentar ao gestor municipal um projeto para oficializar o Centro de Convivência definido pela Portaria 396 como:

[...] dispositivos públicos componentes da rede de atenção substitutiva em saúde mental, onde são oferecidos às pessoas com transtornos mentais espaços de sociabilidade, produção e intervenção na cidade (BRASIL, online, 2005).

Tínhamos claro que:

[...] a mistura das pessoas e de suas diferentes chances de vida nos Centros de Convivência, deverá se fazer com orientação e supervisão técnica, visto que o objetivo não é meramente se juntarem em suas mazelas comuns ou parecidas, pressuposto da formação de gueto (LOPES, 1992, p. 9).

E para tanto é necessário a formação de uma equipe constituída de diferentes profissionais que contribuam para a prevenção dos agravos do sofrimento psíquico. Esta necessidade foi apresentada ao gestor municipal.

Inicialmente o projeto apresentado foi recusado por "falta de recursos". Diante da nossa insistência fomos liberados a começar com os recursos materiais e humanos existentes. No que tange aos recursos materiais dispúnhamos de móveis usados e outros utensílios disponíveis de outros equipamentos, que acomodamos no local destinado às reuniões das equipes do PSF, onde já estávamos. Lutamos em seguida pela locação de um imóvel próximo à UBS, o que necessariamente estimulou novos encaminhamentos burocráticos e o estafante acompanhamento, da nossa parte, de todos os passos do processo. Finalmente, depois de três meses, conseguimos que o gestor municipal alugasse uma casa térrea no quarteirão ao lado da UBS e para lá nos transferimos. Tratava-se de um imóvel 
com cerca de 60 metros quadrados de área construída, cujas instalações eram bem simples. A divisão e a organização dos cômodos deste imóvel podem ser descritas como uma sala de estar e uma sala que acomodamos uma biblioteca com alguns livros e revistas doados pela comunidade. Nesse cômodo também estavam expostos os trabalhos artesanais feitos pelos portadores de transtorno mental que participavam do grupo; ele era também uma sala para atendimento individual, quando fosse necessário. Nesta sala acomodavam-se igualmente os documentos de caráter administrativo. Havia ainda uma cozinha com armários e um fogão conseguido por conta da reforma de outro equipamento do município. Durante o tempo em que ocupamos esse imóvel a cozinha foi muito utilizada, pois à tarde fazíamos intervalos para degustar um breve lanche, geralmente preparado pelos próprios portadores de transtorno mental ou seus familiares ou qualquer outra pessoa da comunidade que estivesse disposta a tanto. Nesse imóvel contávamos ainda com uma garagem coberta, onde se davam as reuniões e eram realizados os trabalhos artesanais e a programação de atividades internas e externas.

Quanto aos recursos humanos, da equipe interdisciplinar solicitada foi disponibilizada uma assistente social que compartilhava de nossa tarefa por três horas semanais. Não dispúnhamos de funcionários, em tempo integral, para nos auxiliar neste trabalho, com exceção de uma auxiliar diária de limpeza. Através de um projeto de extensão firmado com a Universidade Estadual de Maringá, dispúnhamos também de quatro estagiárias do ultimo ano do curso de Psicologia, sob a nossa supervisão. Estas acadêmicas participavam de nossas atividades cumprindo uma carga horária de quatro horas semanais. Conseguimos alguns voluntários para monitorar os cursos de artesanato, violão, desenho e música para adolescentes, e tínhamos planejado a constituição de um coral, dentre outras atividades. Os cursos visavam incluir todas as faixas etárias e assim atender os familiares.

As pessoas com transtorno mental, egressas ou não do hospital psiquiátrico, que faziam parte do "nosso grupo", em geral, apresentavam as seguintes características: eram pacientes jovens na faixa dos 20 aos 40 anos, já com um histórico de no mínimo três ou quatro anos de tratamento psiquiátrico, alguns com várias internações e a maioria com diagnóstico de esquizofrenia. Em geral apresentavam antecedentes familiares de morbidade psiquiátrica, sobretudo de alcoolismo e drogadição, e uma grande incidência de violência familiar. Nesse grupo ainda contávamos com algumas mulheres que se dedicavam apenas aos afazeres domésticos e tinham uma história de internação, mas conviviam com os sintomas do transtorno mental controlados pela medicação. Interessante destacar que nesse grupo de mulheres era freqüente a omissão dos sintomas para o médico, quando do retorno à consulta médica. Este é, talvez, um artifício para evitar novas internações. É necessário ressaltar que nesta região encontramos também casos muito graves, já em estado crônico adiantado, quanto aos quais nada conseguimos fazer, em virtude de nossa limitação e da própria rede de saúde do município. 


\section{Atividades desenvolvidas}

Com o "nosso grupo" fizemos muitos passeios a parques e indústrias da região. Aproveitávamos datas significativas para festejos, principalmente aniversários dos usuários, com direito a bolo e fotografia. Muitos jamais haviam tido o prazer de ter um bolo de aniversário. Brincadeiras e jogos também faziam parte das festas. Buscávamos, desta forma, estimular os mecanismos de ajuda mútua e solidariedade, e, sobretudo, criar, através da troca de experiências, a possibilidade de compreensão dos problemas vivenciados. Buscávamos assim construir uma nova prática, que superasse os limites do atendimento prescrito pela psiquiatria clássica. Buscávamos dar acolhimento ao sofrimento enquanto uma etapa do processo de trabalho. Entendendo o acolhimento como uma diretriz operacional que se propõe a "inverter a lógica de organização e funcionamento do serviço de saúde" (FRANCO; BUENO; MERHY, 1999, p. 346) e desta forma garantir a acessibilidade universal, dentre outros princípios. Enfim, buscávamos construir um espaço que priorizava o doente e seus familiares, sem cair na dimensão assistencial e caritativa que desde longos anos caracteriza o atendimento ao doente mental e sem perder de vista os cuidados técnicos com a doença. Buscávamos propiciar e fomentar a tão propalada reintegração social da pessoa portadora de transtorno mental.

Concomitantemente às reuniões semanais desse grupo, continuamos as visitas domiciliares aos portadores de sofrimento mental e seus familiares, estimulando-os a participar do "nosso grupo". Paulatinamente estas pessoas, tanto o portador de transtorno mental quanto seus familiares, iam se aproximando e estendendo o convite a outras famílias; e - o que é muito importante, digase de passagem - estas famílias sempre faziam indicações de outras famílias que viviam o mesmo problema. Isto significa que as indicações para as nossas visitas nem sempre partiam da equipe do PSF, motivadas por dificuldades em estabelecer a diferença entre transtorno mental e deficiência mental, como já assinalamos anteriormente. Tal dificuldade, aliás, não é tão acentuada entre os familiares, embora exista confusão neste sentido. Chegamos a contabilizar um total de sessenta famílias com pessoas portadoras de transtorno mental com histórico de internação no hospital psiquiátrico adstritas à área de abrangência da UBS. Vale ressaltar que este levantamento não chegou à exaustão, o que pode significar a existência de um número ainda maior de pessoas que necessitam de atenção à saúde mental. Este fato por si só ratifica a necessidade da existência da rede de atendimento à saúde mental, que deve contemplar, entre outros equipamentos, o Centro de Convivência.

\section{FinAl da EXPERIÊNCIA... OU O VERÃo Não ENCONTRAdo}

Não obstante, conquanto este número de visitas às pessoas com transtorno mental - parte das quais era por nós atendida - representasse uma pequena parcela da população a ser atendida nesta área de abrangência para o trabalho que vínha- 
mos desenvolvendo, percebíamos estar atingindo o limite das nossas possibilidades. Este limite foi ficando claro quando a única profissional de que dispúnhamos - a assistente social -, em virtude de seu deslocamento para outras UBSs, deixou de participar do "nosso grupo". As estagiárias de Psicologia, por conta do final do ano letivo e conclusão do curso, foram desligadas do Projeto e em seu lugar novas estagiárias foram colocadas, o que significava novo tempo de aprendizagem. Isto sem contar a falta de outros tipos de recurso até mais simples, como, por exemplo, a falta de argila para desenvolver atividades de caráter terapêutico-ocupacional. No início de 2005 houve a mudança de gestor municipal, e o novo não acenou com a menor perspectiva de investimentos necessários à implementação do Centro de Convivência. Continuamos insistindo no atendimento, mas, apesar da nossa insistência, não encontramos eco nem mesmo entre os colegas da UBS. Diante desta situação e, além disso, diante dos riscos que se correm pelo nãoacompanhamento, devido a uma demanda que a cada dia aumentava, e do fato de estarmos criando expectativas que solitariamente não era possível atender, demos por encerrada nossa determinação de ‘fazer verão' ainda que só.

\section{LIÇÕES SOBRE O SUCESSO E LIMITES DO VÔO SOLITÁRIO}

Confirmando a metáfora da andorinha que sozinha "não faz verão" faremos a seguir algumas pontuações acerca desta experiência, quiçá possam subsidiar o debate tão necessário e oportuno sobre a Reforma Psiquiátrica no Brasil. Iniciamos pelo destaque a freqüência dos depoimentos de outros profissionais da UBS sobre o aumento desta demanda pelos serviços da rede básica e a diferença notada nos pacientes quando buscavam estes serviços após o inicio deste trabalho, o que traduzimos como elogios. Por outro lado, se diferenças estavam sendo notadas e elogios ao nosso trabalho não faltavam, paradoxalmente, o apoio para levar avante este trabalho acontecia em razão inversa. Se nas visitas iniciais notamos a aproximação das equipes do PSF aos chamados doentes mentais, com o passar do tempo as ACSs e as equipes de forma geral foram se distanciando. Cobravam repetidamente orientações, queixavam-se de receios por conta da idéia já arraigada no imaginário popular de que estes pacientes são perigosos e tantas outras justificativas para não investir mais neste setor da saúde. Temos por hipótese que este distanciamento se deve principalmente a expectativa de melhoras rápidas e fantásticas, ou mesmo que, ao tomarem o físico como sinônimo do mental, esperavam a cura, enquanto o que a ciência, por ora, nos oferece é apenas o controle dos sintomas. O fato de o psicólogo não fazer parte da equipe do PSF também pode ter influído neste afastamento das ACSs, pois via de regra a nossa solicitação era entendida como algo além do que deviam e tinham a obrigação de fazer. Entendem também que o atendimento à pessoa com transtorno mental tem o isolamento no hospital psiquiátrico como à única forma de atendimento terapêutico, o que corresponde à idéia predominante no imaginário popular. Este fato deixa evidente a necessidade de maior investimento na capacitação não apenas dos profissionais da saúde mental, mas também capacitar os demais profissionais de outros setores e, sobretudo na educação popular que serve de argamassa na construção de uma cultura antimanicomial e amplia as possibilidades de intervenção. 
É tempo de entender que a loucura é própria da condição humana, o que significa que todo ser humano está sujeito a ela. Isto já era percebido pelo filósofo romano Cícero (106-43 a.C.), quando afirmava que "essas desordens (da mente) são, portanto, limitadas aos homens" (ALEXANDER; SELESNICK, 1966, p. 79). Esta capacitação geral e a convivência com as pessoas com transtorno mental podem favorecer a compreensão de que estas pessoas por sofrerem repetidas internações, com a agravante de a primeira destas ter-se dado muito cedo na sua vida, apresentam dificuldades de se relacionar em grupo. Tais dificuldades são justificadas pelo rompimento de todos os vínculos sociais a que estão submetidas às pessoas que vivem parte de suas vidas isoladas e sob efeito de forte medicação. Quando são liberadas do isolamento do hospital psiquiátrico, elas, via de regra, têm na consulta e na receita médica a única assistência, a qual, além disso, geralmente ocorre com largo decurso de tempo entre uma consulta e outra. Ante a continuidade das sensações e vivências internas que intensamente vão dominando seu psiquismo, tão fartamente descritas na literatura, e a falta de suporte social para entender e enfrentar esta situação observa-se que no decorrer deste processo a pessoa com transtorno mental vai apresentando algumas características que absolutamente não a estimulam à socialização e à autonomia. Dentre estas características podemos citar a falta de iniciativa, a dificuldade de assumir qualquer compromisso e a raridade de sinais de qualquer desejo próprio da idade. Tais pessoas apresentam, também, atitudes mentais bem marcadas pela infantilidade. Enfim, o isolamento, o efeito dos medicamentos e a falta de uma assistência que lhes dê um suporte social vão comprometendo, cada vez e a cada dia mais, a autonomia destas pessoas, levando-as, na maioria dos casos, a uma quase total dependência de outrem. As pessoas por nós visitadas ou as que participavam do "nosso grupo" não fugiam à regra, e sempre apresentavam algumas destas características. São estas algumas das razões que apontam à necessidade de mudar a forma de pensar e atender à saúde mental. Substituir equipamentos hierarquizados para formas flexíveis de acompanhamento do usuário em suas necessidades individuais, com vista à sua reabilitação e melhoria de sua qualidade de vida, priorizando-se a manutenção dos vínculos familiares e sociais. E isto não se resume em criação de novos equipamentos ou de experiências isoladas tal como a que expusemos. Exige, isto sim, o envolvimento dos inúmeros dispositivos institucionais e ações solidariamente articuladas em referencia e contra-referencia e "a ousadia de introduzir o fenômeno do sofrimento mental no cotidiano, na periferia das relações" (LOPES, 1999, p. 66). Ou, ainda, como afirmou um dos consultores ad hoc deste texto "o verão da Reforma Psiquiátrica não se faz entre iguais (andorinhas), mas com sapos, beija-flores e que tais".

\section{Notas}

${ }^{1}$ Os resultados deste estudo podem ser consultados em Boarini (2006).

2 O Programa Saúde da Família é um projeto dinamizador do SUS e entendido como uma estratégia de reorientação do modelo assistencial, operacionalizado mediante a implantação de equipes multiprofissionais em Unidades Básicas de Saúde (médico, enfermeiro, um auxiliar de enfermagem e seis agentes comunitários de saúde, podendo ser ampliada com a participação de dentista, auxiliar de consultório dentário e técnico em higiene dental) (BRASIL, 2004b). 


\section{REFERÊNCIAS}

ALEXANDER, F. G.; SELESNICK, S.T. História da Psiquiatria: uma avaliação do pensamento e da prática psiquiátrica desde os tempos primitivos até o presente. São Paulo: Ibrasa, 1966.

BOARINI, M. L. A loucura no leito de Procusto. Maringá: Dental Press, 2006.

BRASIL. Ministério da Saúde. Secretaria-Executiva. Secretaria de Atenção à Saúde. Legislação em Saúde Mental-1990-2004. 5. ed. ampl. Brasília: Ministério da Saúde, 2004a. p. 17-19. Disponível em: <http://portal.saude.gov.br/portal/ arquivos/pdf/Legislacao.pdf $>$. Acesso em: 07 maio 2006.

Ministério da Saúde. Departamento de Atenção Básica - DAB. Atenção Básica e a Saúde da Família. Brasília: Ministério da Saúde, 2004b. Disponível em: $<$ http://dtr2004.saude.gov.br/dab/atencaobasica.php>. Acesso em: 16 ago. 2007.

Ministério da Saúde. Portaria no 396 de 07 de julho de 2005. Brasília: Ministério da Saúde, 2005. Disponível em: <http://dtr2001.saude.gov.br/sas/ PORTARIAS/Port2005/PT-396.htm>. Acesso em: 29 dez. 2007.

CAMPOS, F. C. B. O modelo da Reforma Psiquiátrica brasileira e as modelagens de São Paulo, Campinas e Santos. Tese (Doutorado)-Universidade de Campinas, Campinas, 2000.

DAUD Jr. N. Considerações histórico-conceituais sobre a instituição psiquiátrica no Brasil e a desinstitucionalizaçao do "doente mental". In: ; BOARINI, M. L. (Org.). Desafios na atenção à saúde mental. Maringá: EDUEM, 2002.

FRANCO, T. B.; MERHY, E. E. Programa Saúde da Família: Contradições e novos desafios. In: . CONGRESSO PAULISTA DE SAÚDE PÚBLICA. Anais. São Paulo: Associação Paulista de Saúde Pública, 2000. p. 145-154.

FRANCO, T.; BUENO, W. S.; MERHY, E. E. O acolhimento e os processos de trabalho em saúde: o caso de Betim. Cadernos de Saúde Pública, Minas Gerais, v.15, n. 2., p. 345-353, 1999.

LOPES, I. C. Centros de Convivência e Cooperativa (Cecco's): alternativas de liberdade. Revista Desbordar, Buenos Aires, n. 5, p. 33-35, sept. 1992.

A contribuição paulistana à reforma em saúde mental brasileira. In:


a rede: trajetórias da saúde mental em São Paulo. Taubaté: Cabral, 1999. 
MARINGÁ (Município). Secretaria Municipal de Saúde. Protocolos da Atenção Básica. Maringá, PR: [s.n.], 2004.

Recebido em: julho de 2006

Aceito em: agosto de 2007 